\title{
Introduction to Empathy: Activation, Definition, Construct
}

\author{
Emily Lord-Kambitsch
}

Empathy indicates an emotional rapport, or identification, with another person. It has been introduced as a central focus for 'sensitivity trainings' and feedback workshops in professional settings, and the relatively new Social and Emotional Learning (SEL) movement in schools. Empathy is promoted as a hallmark of social relationships that if featured in human interactions will presumably make us better at relating to one another. Empathy as advertised seems a worthy means of creating harmony within a community, or between communities, or even nations. This multidisciplinary collection of ideas about and approaches to empathy stems from a workshop on 'Empathy' held at the Joint Faculty Institute of Graduate Studies (JFIGS) Forum at University College London on 1 November, 2013. The JFIGS Forum synthesised various methodological approaches from both postgraduate students and members of academic staff from the Joint Faculties of Arts and Humanities and Social and Historical Sciences at UCL. The workshop evaluated the idea of empathy from an interdisciplinary perspective in order to address questions of human (and even non-human) capabilities for empathy; the role of empathy in the construction of cultural identity; the employment of empathy in the arts; the connection between empathy and communication in cyber communities; and the potentially damaging effects of empathy, either in its lack or its overexploitation, in various contexts. Individual disciplinary approaches represented at the Forum included philosophy, anthropology, psychology, classical studies, fine arts, gender studies, English literature, modern languages, and digital humanities. The event culminated in a roundtable discussion on 'empathy in action', which evaluated empathy as a motivator for altruistic action, and revisited questions and themes featured in the individual papers, a number of which are represented in this collection. ${ }^{1}$ I would like to acknowledge here the editorial support of Professor Maria Wyke in the UCL Department of Greek and Latin, whose guidance and input has been instrumental in the generation of this collection of fresh and diverse approaches to the study of empathy.

\section{Empathy Activated}

My motivation to organise the JFIGS Forum on empathy was grounded in my perception of a growth in advocacy of empathy in educational, corporate, and even academic settings. In my development as a teacher in higher education, I encountered a model for supervisory relationship in the practice of individual feedback (in undergraduate or postgraduate courses of study). In this model, developed by Styles and Radcloff in 2001,

\footnotetext{
${ }^{1}$ For more information about the JFIGS Forum on 'Empathy', please visit the website: http://www.ucl.ac.uk/jfigs/figs-events-publication/empathy (Accessed 15 October 2014).
} 
'affect', defined as 'mutual recognition of feelings...shared empathy with constraints and problems each person faces', is highlighted as one of the four important factors of the student-supervisor dynamic designed to foster independent learning, adaptability, and (from the perspectives of both student and supervisor/teacher) 'a sense of control over the learning that is achieved'. ${ }^{2}$ Empathy associated with affect here seems to suggest a kind of transparency in communication, where feedback can take the form of open, constructive dialogue between teacher and student. The idea that empathy manifests as a result of mutual verbal disclosure is worth keeping in mind, as the validity of this causal relationship will be expounded and challenged by several of the papers in this collection.

Similar attitudes advocating empathy in feedback situations can be found in business as well as academic settings. In 2011, when I worked in the educational non-profit sector, I attended a feedback workshop run by an organisation called 6 Seconds, which provides training to increase 'EQ' (emotional intelligence), and particularly empathy, in professional environments. ${ }^{3}$ The feedback workshop in which I participated opened with the workshop leader's analogy for empathy: 'Two glasses of water symbolise my feelings and your feelings; empathy is a third glass into which we each pour a measure of our feelings'. In this paradigm, empathy occupies a space outside of both individuals' experience; empathy allows people to meet halfway emotionally, and to acknowledge and observe the other's emotional experiences, and the interaction between them, from a distance. The leader of the workshop then instructed the participants to visualise a feedback situation between a supervisor and employee, where empathy would manifest as a synthesis of observations, analyses, and impressions of the quality of work, offered by both employer and employee. In this scenario, the work would not be perceived as a reflection on the employee, and the employee is thus not encouraged to identify personally with the object of potential criticism.

The above examples demonstrate appropriations of empathy in the same context (giving/receiving feedback) within two distinct settings (educational and business). In both instances, empathy is generally characterised by mutual recognition and appreciation of emotional experience through dialogue, but it is not explicitly defined. An article published in Forbes magazine in March 2013 reported the highlights of a panel discussion on 'Empathy in Business' among three CEOs and the President of George Mason University. The panellists reportedly valued empathy as 'the most important characteristic in an entrepreneur', a valuable tool in developing businesses that benefit community, and an important quality in a corporate leader. They recognised empathy as an 'innate ability' and 'active empathy' as a quality that can be taught from primary education onwards. 'However, the article defines neither 'empathy' nor 'active empathy', and it does not report the definition of empathy as a central point of the panel discussion. This begs the question: how can we teach a skill, and expect people to be familiar with and properly employ it in a business setting without clearly defining the skill? The applicability of empathy to personal and professional relationships is largely perceived to

\footnotetext{
${ }^{2}$ Presented in Greg Light, Roy Cox, and Susanna Calkins. Learning and Teaching in Higher Education. Second Edition. (London: SAGE Publications, 2009), 158-159.

3،Get Started with Emotional Intelligence," 6 Seconds, accessed 25 August 2014. http://www.6seconds.org/learn/get-started-emotional-intelligence/

${ }^{4}$ Monica Tanase-Coles, "Empathy in Business: Indulgence or Invaluable?” Forbes, 22 March 2013, accessed 25 August 2014. http://www.forbes.com/sites/ashoka/2013/03/22/empathy-in-businessindulgence-or-invaluable/
} 
be beneficial to the well being of all involved, through some method of awareness of the other's emotional status. However, the growing effort to 'activate' empathy without defining it may place potential empaths at risk of paradoxically mis-empathising due to the circulation of multiple, or even conflicting understandings of empathy and the actions it ought to motivate. This consideration brings us to the question: how can we define empathy? Is it a purely internal experience, or is it also characterised by the communications or actions taken, motivated at least in part by reflection on the other's emotional experiences? Can we read some version of empathy into scenarios or rhetoric which do not mention it explicitly but describe some attributes commonly associated with it (awareness of the other's emotional experience)? How is empathy related to other emotional capacities involving shared emotional intelligence or experience, such as sympathy or compassion?

Lastly, can we perceive significance in the absence of the term 'empathy' in contexts where its use may be expected? For example, a study on emotional contagion and expressive congruence tested the capacity for human subjects who had seen images of people manifesting facial expressions of various emotions ${ }^{5}$ to mimic those expressions, and report their own emotional experiences corresponding to those represented by the original facial expressions in the images. The literature review for the article includes references to other psychological studies on the association between automatic mimicry and empathy, but the article does not use 'empathy' to describe the self-reported experience of the test subjects. Instead, the article avoids the use of 'empathy', and moreover questions the validity of self-reported emotional experience as evidence for the 'contagion' of emotional experience outside of the mimicry of facial expression. ${ }^{6}$ The authors of this study may thus be suggesting that empathy, although a significant human experience involving shared emotional experience, cannot be quantified or studied objectively.

I encountered a similar concept of 'emotional contagion' in my own postgraduate research in classical studies on the healing of grief (dolor) in the philosophical treatises, letters, and consolatory writings of the Roman philosopher Seneca. Seneca, adhering to the Stoic tradition of perceiving emotions as detrimental to a good life, frequently draws a parallel between emotions and infectious diseases. ${ }^{7}$ According to Seneca the failure among individuals to contain anger threatens a destruction of humanity more certainly

\footnotetext{
${ }^{5}$ The methodology for this study (the use of images with emotions represented in facial expressions) was influenced by Matsumoto and Ekman's studies on universal recognition of emotions in facial expressions. David A. Lishner, Amy B. Cooter, and David H. Zald, "Rapid Emotional Contagion and Expressive Congruence Under Strong Test Conditions", Journal of Nonverbal Behavior (2008) 32: 230.

${ }^{6}$ The article acknowledges what the authors regard as a significant limitation of the study, namely the questionable reliability of self-reported emotional experience: 'Unfortunately, self-reports, which remain the only way to assess the experiential aspects of emotion, provide poor temporal insight into when an emotional experience begins. Consequently, it remains unclear whether a physiological response that occurs after presentation of a stimulus precedes or follows an emotional experience evoked by the stimulus' (Lishner, Cooter, and Zald, "Rapid Emotional Contagion", 237).

${ }^{7}$ Seneca, De Tranquillitate Animi, 7.4. All translations mine. According to Asmis, Bartsch, and Nussbaum, in Stoic philosophy, and particularly Seneca's interpretation of it, one must endeavour to free oneself from the experience of emotions, and aspire to the mental clarity and emotional equilibrium (apatheia) of the wise man (sapiens). Elizabeth Asmis, Shadi Bartsch, and Martha Nussbaum. "Seneca and His World", in Seneca Anger, Mercy, Revenge, trans. Robert Kaster and Martha Nussbaum. (London: University of Chicago Press, 2010) xii.
} 
than any illness does. ${ }^{8}$ We can see a clear motivation for Seneca to advocate the practice of something like empathy, in this case an understanding of how emotions work, and how an individual can and should manage the expression of his emotions with consideration of the emotions of others and the collective peace of mind (tranquillitatem animi). Seneca advises his addressees that if they cannot eradicate difficult passions, they must work to assume a neutral facial expression, since emotions appear on the face, and can be transmitted to others who perceive them there. ${ }^{9}$ In his consolations Seneca uses historical examples and hypothetical scenarios to give specific instructions for individuals to conceal suffering (dolor) lest it spread to the family and the community. ${ }^{10}$ However he employs in these instances no words we may identify with empathy, such as compassion (misericordia), mercy (clementia), or even comfort (solacium), all of which do occur elsewhere in Seneca's body of work if not in other passages in the consolations. Like the authors of the 2010 study of emotional contagion, Seneca seems to avoid attaching a name to the capacity for people to 'catch' emotions from the faces of others, and the practice of dispelling emotions from the face (if not the mind) to prevent others from catching them. By contrast, Seneca's tone demonstrates confidence in the validity he ascribes to these types of empathic experiences. Moreover, Seneca may be avoiding certain political implications of using the terms above, particularly 'compassion' and 'mercy' (see Irarrázabal's article in this collection).

\section{Empathy Defined}

When empathy is explicitly defined, even within a given academic discipline, its meaning still differs according to specific context. The Oxford English Dictionary identifies empathy as a capacity involving cognition and emotion: 'The quality or power of projecting one's personality into or mentally identifying oneself with an object of contemplation, and so fully understanding or appreciating it... The ability to understand and appreciate another person's feelings, experience, etc.' ${ }^{11}$. It is noteworthy that personal identification according to this definition of empathy is only applicable to 'objects of contemplation', particularly in the context of aesthetics. Two papers in this collection will address the function of empathy experienced by the viewer in relationship to works of art (Ow Yeong and Tabernacle).

Affective identification with other humans belongs instead to the $O E D$ definition of sympathy: 'The quality or state of being affected by the condition of another with a feeling similar or corresponding to that of the other; the fact or capacity of entering into or sharing the feelings of another or others. ${ }^{12}$ Thus, according to this distinction, in the case of empathy, we can practice emotional intelligence, or the comprehension of the emotional experience of another person, and we can appreciate, or even value and respect another person's emotional experience. Empathy and sympathy both require

\footnotetext{
${ }^{8}$ Seneca, De Ira, 1.2.1.

${ }^{9}$ Seneca, Consolatio ad Polybium, 5.4.

${ }^{10}$ Seneca, Consolatio Ad Helviam, 1.1; Consolatio Ad Polybium, 5.4; Consolatio Ad Marciam, 4.2.

11 "empathy, n.", OED Online, 2014, Oxford University Press, accessed 25 August 2014. http://www.oed.com/view/Entry/61284?redirectedFrom=empathy.

12 "sympathy, n.", OED Online, 2014, Oxford University Press, accessed 25 August 2014. http://www.oed.com.libproxy.ucl.ac.uk/view/Entry/196271?rskey=Ughj12\&result=1\#eid.
} 
perception of an interaction between the self and the other; however, according to their respective definitions above, sympathy, while it endeavours to align emotional experiences, is potentially the more socially exclusive of the two cognitive-emotional capacities. Sympathy, or the process of affective identification with another person, ${ }^{13}$ can actually lead to conflict. If we identify with one person or group, we may exclude from our sympathy, ignore the experience of, and even attack, others deemed hostile to the social and emotional well being of the person or group with whom we identify.

When I taught for a Social and Emotional Learning (SEL) programme in American high schools in 2010-2011, I worked with teenagers to identify the causes of, and potential solutions to, social exclusion and bullying in schools. Like other SEL curricula, ours emphasised one particular aspect of emotional experience: 'the cognitive processing of emotion...the "reasoning about" emotion and the behaviours one associates with such reasoning. ${ }^{14}$ Our programme defined empathy as the act of exercising a cognitive awareness both of others' emotional states and of the impact our words and actions may have on other people. In order not to reinforce the teens' personal identification with either 'bully' or 'victim' roles at school, we encouraged them to think about cultivating empathy when they see bullying going on around them-stepping in as the empathic bystander and telling the bully to stop. In various high schools, the teens would often react similarly to this idea. While they would admit that they felt sorry for the victims of bullying at their school, they were reticent to take action, on the basis that the bully would mistake their empathy for sympathy and identify them with the victim and thus victimise them. The observation of the cognitive processes underlying empathy and sympathy in this case demonstrate that the context, and the amount of risk to personal well being, can hamper our ability to take action motivated by empathy, regardless of our ability to recognise and appreciate the emotional experiences of others. But given that popular notions of empathy are to such a high degree oriented toward pro-social action, does awareness of others' emotional experiences without action or re-action still count as empathy?

In the social sciences there is significant debate as to how empathy should be defined, and whether empathy can be a boon or an impediment in the academic practice of understanding patterns of human behaviour. For instance, in anthropology, some agree 'that it is exactly such a preserved distinction between self and other that fosters the possibility for an "'accurate', empathetic understanding of another's first-person subjective experience'. ${ }^{15}$ Others find empathy problematic in anthropological research, as it may result in the researcher developing 'secondary rationalizations that serve as explanations for everyday social practices'... 'inner meanings' [that] 'may often differ from outwardly observable effects. ${ }^{16}$

\footnotetext{
${ }^{13}$ Or at least perceived affective identification, for here we come to the question of whether or not we can know with absolute certainty another person's emotional experience, even with his or her reported experience, and thus we identify with what we think the other is experiencing, regardless of the other's actual experience.

${ }^{14}$ Diane M. Hoffman, "Reflecting on Social Emotional Learning: A Critical Perspective on Trends in the United States," Review of Educational Research, (2009) 79.2, 538.

${ }^{15}$ Douglas Hollan and C. Jason Throop, "Whatever Happened to Empathy?: Introduction," Ethos, (2008) $36.4,386$. See the rest of this article for general questions anthropologists have posed about the definition of empathy, particularly concerning the degree of self-identification involved in the cognitive process.

${ }^{16}$ Hollan and Throop, "Whatever Happened to Empathy?," 389.
} 
This quality of self-projection in empathy seems to be missing from the OED definition of empathy. Self-projection emerges as a key component in the conscious practice of empathy as it is described in the rhetoric of the business and educational settings cited above. Self-projection I define as the act of imagining, 'how would I feel in that situation?' In the case of sympathy, the process of affective identification renders the emotional experience actual (i.e. 'I $d o$ feel this way because a person in this situation is feeling this way'). Economist Ken Binmore has even developed a concept for evaluating the distinction between what I call empathic self-projection and affective identification (sympathy). He "contrasts "sympathetic identification," the process whereby "one individual so successfully imagines himself into the shoes of another that he no longer fully distinguishes his interests from the person with whom he identifies", and "empathetic identification," which "stops short of the point where we supposedly cease to separate our interests from those with whom we identify". ${ }^{17}$ In the survey of interdisciplinary perspectives gathered at the JFIGS Forum and represented in this issue of Think Pieces, the relationship between imagination and empathy, through the process of self-projection, is almost always present as a featured element of discussion. This aspect of empathy should continue to be considered of importance both to scholars seeking to gain a better understanding of how empathy functions socially, psychologically and even physiologically, and to 'practitioners', or those who aim to cultivate empathy actively in their own lives and promote it in their communities.

\section{In This Collection: Empathy Constructed}

The papers delivered at the JFIGS Forum and contributed to this collection aim to explore concepts of empathy in context, whether this is fine arts, digital communications, ancient philosophy, or clinical psychology. The cohesion in this collection of interdisciplinary perspectives is organically thematic, as it was at the original Forum. Each of these papers explores the tension between the extent to which empathy is constructed by a context, and the extent to which individuals operating within that context bring empathy into the contextual framework (is healthcare, clinical psychology, or education an inherently empathic system? Is photojournalism or the criminal justice system inherently without empathy?) To what extent is the context designed to engage the empathy of those operating within it?

These papers also evaluate the connection between imagination, self-projection, and empathy, and address theories of psychosomatic processes of empathy in order to understand its function. How does empathy work cognitively, and/or affectively? How do we gain insight into another person's experience (do we need language, or can we use nonverbal modes of communication, including art)? Can humans respond with genuine empathy toward fictionalised portrayals of others' emotional experiences? Along these lines, is the media overwhelming our capabilities for empathy with too many images, stories, and videos, particularly of human suffering, to the point at which we can no longer empathise, due to the overload on our senses?

\footnotetext{
${ }^{17}$ Binmore (1994, 55-56), quoted in Philippe Fontaine, "The Changing Place of Empathy in Welfare Economics," History of Political Economy, (2001) 33.3, 387-388.
} 
Another significant theme common to many of the papers in this collection is the connection between empathy and pro-social action. Can we define empathy solely by the capacity to recognise and appreciate others' emotional states (through a process of selfprojection) without taking action motivated by this capacity? Alternatively, is action motivated by this sort of emotional awareness a necessary component of empathy?

Wai Kit Ow Yeong explores the potential for photography to stimulate empathic responses in viewers, by incorporating the work of Susan Sontag in a discussion of the cultural impact of a photograph of human suffering in Sudan taken by photojournalist Kevin Carter. His article analyses the relationship between viewer and image, and between photographer and human subject, in order to evaluate the presence, or absence of empathy in both the act of viewing an image of human suffering, and the act of photographing the subject at the expense of otherwise offering comfort or aid. The issue of whether the viewer's capacity for empathy in response to the image is impeded or misdirected by the separation of the image from its original context also emerges here, engaging with an overarching theme of this collection, the relationship between empathy and imagination/reality.

The relationship between empathy and imagination is questioned further in Kay Tabernacle's discussion of artist Hannah Höch's creative process and the viewer's relationship to it in the act of viewing. This article synthesises concepts from physiology, art history, and psychoanalytic theory present in the work of Charles Darwin, David Freedberg and Vittorio Gallese, Sigmund Freud, and others to evaluate the function of body-image in Höch's photomontages as they invite viewers to participate in corporeal self-projection and identification with the figures in the art. Tabernacle includes in this article her own animation designed to render visible the potential 'architectures' of imagination and its relationship to empathy and other psychic states she introduced in her discussion.

The moral implications of empathy as a motivator for humanitarian action are the focus of Manuela Irarrázabal's article, which analyses the argument for self-projection as a foundation for the ceasing of retributive violence, as laid out in the work of the Roman Stoic philosopher Seneca. Irarrázabal contrasts Seneca's appraisal of pity (misericordia) and mercy (clementia) as society's potential responses to criminal behaviour, and compares Seneca's advocacy for self-projection on the basis of human failure to Judith Butler's work on vulnerability creating a platform for non-violent solutions to political and social conflict. This article provides an interdisciplinary reflection on empathy and accountability in human relationships, and the relationship between empathy and action.

Guy Smith engages perspectives from the field of psychotherapy to explore the means by which verbal and nonverbal communication styles invite, or discourage, empathy as recognition and appreciation of others' emotional states. He evaluates three 'listening practices' that challenge normative 'meaning-centred' modes of comprehending emotional experience, and builds on Leo Bersani's critique of meaningfocused communication as a motivator for conflict through its promotion of a worldview characterised by 'hierarchical binaries' rather than synthesis. His article also comments on the potential for these new communication styles to promote empathic relationships if applied beyond psychotherapy settings and integrated into mainstream discourse.

All of the papers in this collection share core themes related to concepts of empathy and its functions, as mentioned above, and they inform each other and enhance 
understanding of the complexity of these issues through the interdisciplinary landscape of their discussions. In some cases, the repeated engagement with the same sources, most notably Susan Sontag's Regarding the Pain of Others, through various methodological lenses, indicates the potential for the articles in this collection to open deeper levels of discussion, and to inform a review of the 'core texts' related to the study of empathy from an interdisciplinary perspective. The commonality between these articles that I find most compelling is the interest in the ethics of empathy, including such questions as, Should we be exercising more empathy in our lives? Is it morally reprehensible in some situations/cultures not to take action motivated by an empathic understanding of another's situation? Moreover, all of the articles here, as well as other discussions held at the corresponding JFIGS Forum, agree that in many contexts empathy carries social benefit, and share the suggestion that academic study of empathy may be one way to inform the world beyond academia of ways in which individuals and communities should process emotions, act, and communicate more empathically.

\section{Bibliography}

Asmis, Elizabeth, Shadi Bartsch, and Martha Nussbaum. "Seneca and His World". In Anger, Mercy, Revenge, translated by Robert Kaster and Martha Nussbaum, vii-xxvi. London: University of Chicago Press, 2010.

"empathy, n.", OED Online, 2014, Oxford University Press, accessed 25 August 2014. http://www.oed.com/view/Entry/61284?redirectedFrom=empathy.

Fontaine, Philippe, "The Changing Place of Empathy in Welfare Economics," History of Political Economy, (2001) 33.3, 387-409.

Hoffman, Diane M. "Reflecting on Social Emotional Learning: A Critical Perspective on Trends in the United States," Review of Educational Research, (2009) 79.2: 533-556.

Hollan, Douglas and C. Jason Throop, "Whatever Happened to Empathy?: Introduction,” Ethos (2008) $36.4,385-401$.

Light, Greg, Roy Cox, and Susanna Calkins. Learning and Teaching in Higher Education. Second Edition. London: SAGE Publications, 2009.

Lishner, David A., Amy B. Cooter, and David H. Zald. "Rapid Emotional Contagion and Expressive Congruence Under Strong Test Conditions": Journal of Nonverbal Behavior (2008) 32: 225-239.

“sympathy, n.”, OED Online, 2014, Oxford University Press, accessed 25 August 2014. http://www.oed.com.libproxy.ucl.ac.uk/view/Entry/196271?rskey=Ughj12\&result=1\#eid.

Tanase-Coles Monica, "Empathy in Business: Indulgence or Invaluable?” Forbes, 22 March 2013, accessed 25 August 2014. http://www.forbes.com/sites/ashoka/2013/03/22/empathy-in-business-indulgence-or-invaluable/.

6 Seconds. "Get Started with Emotional Intelligence", accessed 25 August 2014. http://www.6seconds.org/learn/get-started-emotional-intelligence/. 